\title{
Performance of International Tourists' Perception and Behavior toward Road Safety in Phuket, Thailand
}

\author{
Kritana Prueksakorn, Kiyota Hashimoto, Sudarat Kamnerdtong, Panuwat Phakdee-auksorn
}

\begin{abstract}
When traveling in a foreign country, road transport is most frequently and conveniently used particularly, but road conditions and manners are stunningly different among countries, which increases potential risks to meet accidents. If tourists feel such risks, it may be that they will not be repeaters and their impressions will also be shared with others, leading to a potential decrease of tourists. Phuket, Thailand, a worldly wellknown beach resort, faces problems in road conditions and manners, with a high rate of traffic accidents and casualties, and governmental actions have to be taken. This paper reports a questionnaire survey result about how international tourists feel and understand road conditions in Phuket during their stay, which is expected to offer good evidence on which governmental actions should be based. The survey results revealed (mostly through the behaviors and recommendations) that the majority of international tourists to Phuket felt risks in terms of road conditions, regardless of whether they drove by themselves or not, and most of them wanted the basic information on road conditions as well as regulations, so that they could prepare themselves. Relations between demographic characteristics and questionnaire replies were also investigated, suggesting that there be a necessity of reducing risks particularly for elderly tourists, and that the driving manner of local residents including professional drivers should be improved.
\end{abstract}

Index Terms: Behavior and perception, International tourist, Phuket, Road safety.

\section{INTRODUCTION}

Road transport is the most frequently used and preferred way for tourists' transportation over the world. Whether it is a bus, a taxi, a van, a rental car or motorbike, offering and maintaining road transport vehicles is one of the fundamental components of the tourism industry $[1,2]$.

Revised Manuscript Received on June 22, 2019.

Kritana Prueksakorn, Andaman Environment and Natural Disaster Research Center, Interdisciplinary Graduate School of Earth System Science and Andaman Natural Disaster Management, Prince of Songkla University, Phuket Campus, 83120, Thailand

Kiyota Hashimoto, Andaman Environment and Natural Disaster Research Center, Interdisciplinary Graduate School of Earth System Science and Andaman Natural Disaster Management, Prince of Songkla University, Phuket Campus, 83120, Thailand

Sudarat Kamnerdtong, Faculty of Hospitality and Tourism, Prince of Songkla University, Phuket Campus, 83120, Thailand

Panuwat Phakdee-auksorn, Faculty of Hospitality and Tourism, Prince of Songkla University, Phuket Campus, 83120, Thailand
It has been considered that road transport is important for all tourists when traveling abroad, whether for a short or a long trip [3]. This is particularly true in Phuket, Thailand, where public transportation systems are limited. However, road transport is often the biggest source of tourists' accidents, partly because of different road manners among countries and more because of poor road conditions and driving customs. Indeed, Suriyawongpaisal and Kanchanasut (2013) mentioned that international tourists could become the victims of road accidents within three days of arrival in Thailand, either as pedestrians, motorcyclists, cyclists or as passengers using the public transit [4].

Phuket, Thailand, which is one of the most famous tourist destinations in Thailand inviting 9.4 million people from all around the world in 2015, has been facing a serious issue in road transport. There were 436,330 registered vehicles, with 169 deaths, 1,022 serious injuries, and 5,037 minor injuries from road accidents in 2014. The travel pattern of the highest number of accident victims was motorcycles (87\%), followed by bicycles (4\%), cars (4\%), pedestrians (3\%) and tricycles $(3 \%)$. Phuket had the second highest arrest rate in Thailand with $9,848.19$ cases per 100,000 population. This was a factor that results in the province having the highest helmet wear rate in the country (56\%), but the number of deaths was the top of the country as well. Types of cases that had been mainly arrested (at the rate of per 100,000 population) in descending order, including no helmet $(9,848.19)$, too fast driving (835.70), wrong-way driving (600.48), unuse of seatbelts (492.12), neglecting traffic signals (262.45), and drunken driving (90.12) [5]. The average value of property damage per case of road accident from 2008 to 2010 is 8,683 THB (around 275 USD) [6]. When that value is applied to the number of accidents occurring in 2014 (2,514 cases), 2015 (4,803 cases), and 2016 (4,419 cases) [7], the value of property damage was 21.8, 41.7 and 38.4 million THB.

Goldstein (2007) stated that perception is a learning process of human to comprehend the stimulus appearing on any sensation. It is called as the process that a person contacts to the environment or the surrounding stimulus such as individual, object, and natural phenomenon. Perception will set personal demand, motivation, action, or behavior $[8,9,10]$. No matter how much marketing activities have been undertaken, negative perception caused by bad experiences will not be easily changed [10]. 
If tourists to Phuket have more negative perceptions on road transport there, they may well not visit again and the prevalence of such negative perceptions may discourage potential tourists from visiting.

Considering international tourists' driving of cars and motorcycles to be a critical source of road accidents, the Thai government has strengthened road regulations against tourists: 50,000 THB fine or 3 months of jail against driving without a driving license from 2019 [11]. Indeed, it is alleged that many international tourists rent and drive a car or a motorcycle even when they do not have a valid driving license in their home country [12]. However, it is also true that many local residents also drive without a license, too often drive recklessly, and drive drunken. It is mandatory that the Thai government take more actions to improve the road conditions, but, for the time being, it is also advised that international tourists have more knowledge. It means that, regardless of driving by themselves, international tourists should have a more appropriate, realistic recognition or perception of the current road conditions in Phuket, or Thailand in general, in order to protect themselves.

Ritchie et al. (2010) stated the travel behavior is the way in which tourists behave according to their attitudes before, during, and after traveling [13]. Tourist experiences can be seen through their reactions, for instance, behaving in contrast to their daily and normal behavior while traveling overseas [14]. As travel behavior can change over time and across cultures, while Thailand was one of the Asian countries with the worst road safety records and had the second highest number of deaths after Namibia [15], it is important to understand how international tourists behave when they travel in Thailand.

It is thus an urgent issue how to know (and improve, if needed) international tourists' perceptions of road transport in Phuket, or Thailand in general, but there has been no study on international tourists' perceptions of road transport in Phuket, which prevents an appropriate action to improve them. This paper reports the result of our questionnaire survey on international tourists' perceptions on road transport in Phuket which was conducted before their leave. The number of the samples is 400 among the tourists in November and December in 2016. We conducted ANOVA analyses to reveal the relations between tourists' characteristics and their road transport perceptions. It is expected that the result of this paper provides suggestive information to set up policies to improve road conditions as well as international tourists' perceptions.

\section{RESEARCH METHODOLOGY}

A questionnaire survey was conducted with international tourists staying in Phuket and leaving there in November or December, 2016. All the questionnaires were provided in English, and the survey was done at the Phuket International Airport with their consents.

In 2015 , the number of international tourists who visited Phuket was 9,488,956 persons [16]. Owing to the formula of Cochran [17], the number of samples that can be regarded as statistically sufficient (confidence level at 95\%, Alpha level at 0.05 , and significant level at $95 \%$ ) is 384.16 . Thus, the number of interviewees in this study was set as 400 subjects.

The questionnaire consisted of both open and close-ended questions so as to obtain additional comments other than those prepared. The set of questions and variables in the questionnaire were reviewed and designed based on the related studies [10, 18, 19], and they are presented in the next section.

\section{RESULTS AND DISCUSSION}

The characteristics of the subjects are presented in Table 1. There was no significance in the sampling numbers between male and female ( $53 \%$ and $47 \%$ ). The largest group of subjects was of the age range of 21-30 years (49\%) followed by the group of 31-40 years $(23 \%)$. The majority of the subjects were from Europe $(30 \%)$, followed by the group from Asia (25\%). The subjects' marital status was fairly distributed between single (42\%) and married (44\%). Most of the subjects had diplomas (32\%), followed by those who had graduated or finished a higher education program (27\%). Most of the subjects' occupations were employees (37\%), followed by professionals/specialists (26\%). The major ranges of the tourists' monthly income are 1,5012,500 USD (24\%), 501-1,500 USD (21\%) and over 4,500 USD (19\%).

Table. 1 Respondents' profile

\begin{tabular}{|c|c|c|c|c|}
\hline \multicolumn{3}{|c|}{ Demographic Profile } & Frequency & Percentage \\
\hline \multirow[t]{3}{*}{ Gender } & Male & & 213 & 53.2 \\
\hline & Female & & 187 & 46.8 \\
\hline & Total & & 400 & 100 \\
\hline \multirow[t]{7}{*}{ Age } & 20 years or younger & & 16 & 4.0 \\
\hline & 21-30 years & & 195 & 48.7 \\
\hline & $31-40$ years & & 91 & 22.8 \\
\hline & 41-50 years & & 30 & 7.5 \\
\hline & $51-60$ years & & 47 & 11.8 \\
\hline & Older than 60 years & & 21 & 5.2 \\
\hline & Total & & 400 & 100 \\
\hline \multirow[t]{2}{*}{ Region } & Asia & & 98 & 24.5 \\
\hline & Europe & & 121 & 30.3 \\
\hline $\begin{array}{l}\text { er: B10180 } \\
\text { 'ijrte.B101 }\end{array}$ & EIESP & 97 & $\begin{array}{l}\text { Published By: } \\
\text { Blue Eyes Intellig } \\
\text { \& Sciences Public }\end{array}$ & ring \\
\hline
\end{tabular}




\begin{tabular}{|c|c|c|c|}
\hline & Australia & 90 & 22.5 \\
\hline & North America & 67 & 16.7 \\
\hline & South America & 11 & 2.8 \\
\hline & Africa & 13 & 3.2 \\
\hline & Total & 400 & 100 \\
\hline Marital & Single & 169 & 42.3 \\
\hline \multirow[t]{6}{*}{ Status } & Married & 174 & 43.5 \\
\hline & Separated & 4 & 1.0 \\
\hline & Divorced & 21 & 5.2 \\
\hline & In the relationship & 24 & 6.0 \\
\hline & Others & 8 & 2.0 \\
\hline & Total & 400 & 100 \\
\hline \multirow{7}{*}{ Education } & Primary school & 3 & 0.8 \\
\hline & High school & 81 & 20.2 \\
\hline & Diploma & 129 & 32.2 \\
\hline & Undergraduate & 77 & 19.2 \\
\hline & Graduate or higher & 107 & 26.8 \\
\hline & Others & 3 & 0.8 \\
\hline & Total & 400 & 100 \\
\hline \multicolumn{4}{|l|}{ Occupation } \\
\hline & Student & 26 & 6.5 \\
\hline & Employee & 148 & 37.0 \\
\hline & Housewife/ unpaid & 17 & 4.3 \\
\hline & Business man/ woman & 60 & 15.0 \\
\hline & Government \& military & 13 & 3.2 \\
\hline & Professionals/ specialist & 102 & 25.5 \\
\hline & Agricultural worker & 3 & 0.8 \\
\hline & Retired & 17 & 4.2 \\
\hline & Unemployed & 12 & 3.0 \\
\hline & Others & 2 & 0.5 \\
\hline & Total & 400 & 100 \\
\hline Monthly & 500 USD or lower & 30 & 7.5 \\
\hline \multirow[t]{6}{*}{ income } & $501-1,500$ USD & 85 & 21.2 \\
\hline & $1,501-2,500 \mathrm{USD}$ & 96 & 24.0 \\
\hline & $2,501-3,500$ USD & 75 & 18.8 \\
\hline & $3,501-4,500$ USD & 38 & 9.5 \\
\hline & Over 4,500 USD & 76 & 19.0 \\
\hline & Total & 400 & 100 \\
\hline
\end{tabular}

International tourist's perception on road safety in Phuket is presented in Table 2. Most of the international tourists highly -

Table. 2 Mean summary of Tourist's perception on road safety

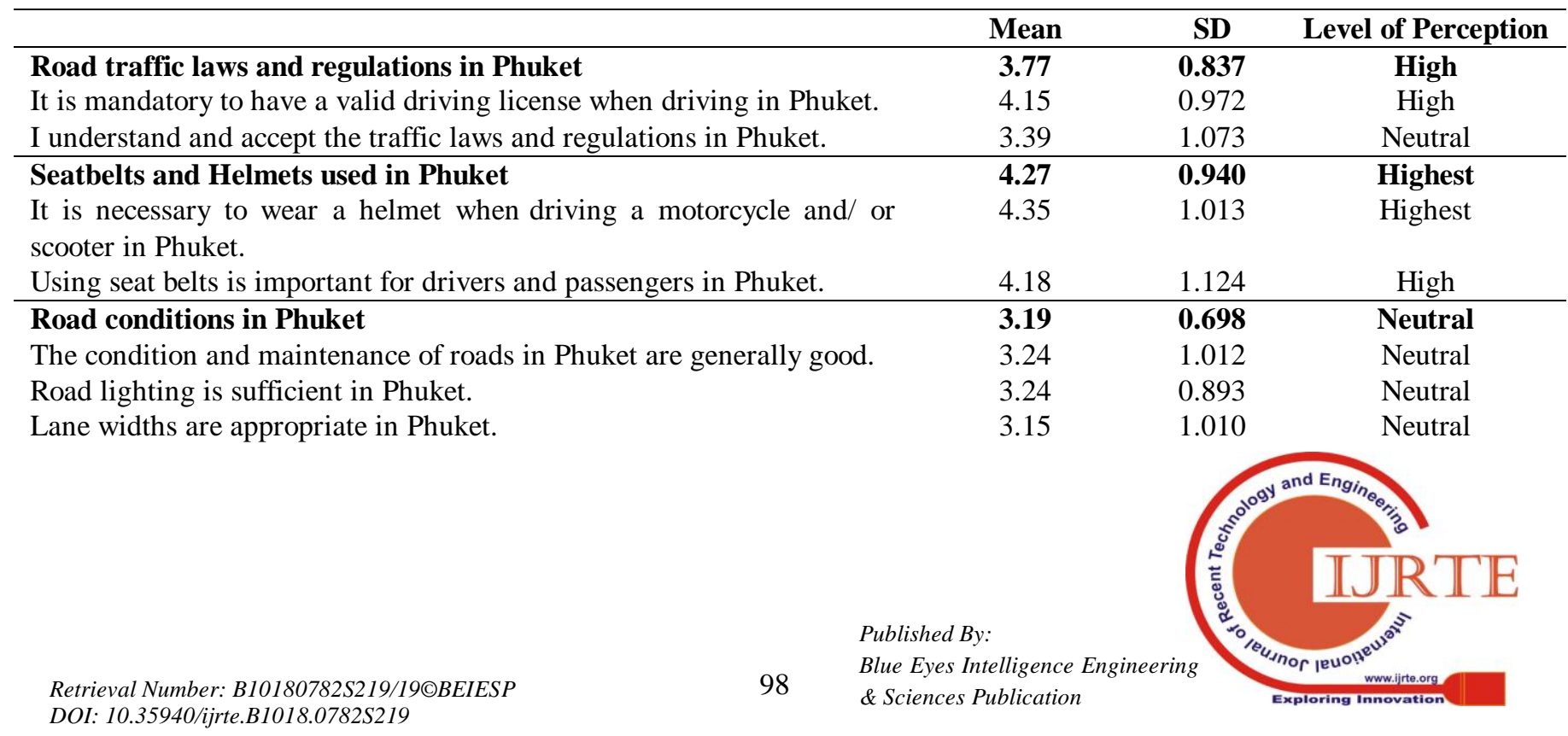


Road pavement is safe enough in Phuket.

\begin{tabular}{|c|c|c|}
\hline 3.15 & 0.932 & Neutral \\
\hline 3.43 & 0.782 & High \\
\hline 3.44 & 0.961 & High \\
\hline 3.42 & 0.920 & High \\
\hline 3.57 & 0.611 & High \\
\hline 4.16 & 0.911 & High \\
\hline 3.61 & 0.875 & High \\
\hline 3.57 & 0.862 & High \\
\hline 2.95 & 1.128 & Neutral \\
\hline 3.29 & 0.726 & Neutral \\
\hline 3.45 & 1.123 & High \\
\hline 3.21 & 1.000 & Neutral \\
\hline 3.19 & 0.954 & Neutral \\
\hline 3.77 & 1.035 & High \\
\hline 3.77 & 1.035 & High \\
\hline 3.08 & 0.895 & Neutral \\
\hline 3.23 & 0.909 & Neutral \\
\hline 2.93 & 1.195 & Neutral \\
\hline 4.28 & 0.954 & Highest \\
\hline 4.28 & 0.954 & Highest \\
\hline 2.98 & 0.835 & Neutral \\
\hline 3.15 & 0.955 & Neutral \\
\hline 3.10 & 0.959 & Neutral \\
\hline 2.95 & 1.065 & Neutral \\
\hline 2.74 & 1.070 & Neutral \\
\hline 3.15 & 0.850 & Neutral \\
\hline 3.15 & 0.850 & Neutral \\
\hline
\end{tabular}

Traffic conditions in Phuket.

Traffic lights in Phuket are in a good condition.

Road traffic signs are easy to understand in Phuket.

Other road safety conditions in Phuket.

Enforcing the speed limit helps reduce the number of driving accidents in Phuket.

It is easy to use the measure of kilometer for the distance and speed in

Phuket road.

Using public transportation services is safe in Phuket.

Local people drive carefully in Phuket.

Emotions and feelings during using the roads in Phuket.

I do not feel confused about driving on the left side of the road in

Phuket.

I feel safe to travel on the road in Phuket.

I do not feel stressed in Phuket traffic jams.

Orientation about road safety in Phuket.

It is a must to be informed of how to drive safely in Phuket before arrival.

\begin{tabular}{|c|c|c|c|}
\hline Ease to be familiar with road conditions in Phuket. & 3.08 & 0.895 & Neutral \\
\hline It is easy to be accustomed to an unfamiliar vehicle in Phuket. & 3.23 & 0.909 & Neutral \\
\hline It is not dangerous to travel on the roads in Phuket for the first time. & 2.93 & 1.195 & Neutral \\
\hline Distracted driving on the road in Phuket. & 4.28 & 0.954 & Highest \\
\hline It is not good to use a mobile phone while driving in Phuket. & 4.28 & 0.954 & Highest \\
\hline $\begin{array}{l}\text { Feeling safe as a passenger, driver, and pedestrian on the road in } \\
\text { Phuket. }\end{array}$ & 2.98 & $\mathbf{0 . 8 3 5}$ & Neutral \\
\hline As a passenger, I feel safe using the roads. & 3.15 & 0.955 & Neutral \\
\hline As a driver, I feel safe using the roads in Phuket. & 3.10 & 0.959 & Neutral \\
\hline As a pedestrian, I feel safe using the roads in Phuket. & 2.95 & 1.065 & Neutral \\
\hline As a pedestrian, I feel safe when crossing a street in Phuket. & 2.74 & 1.070 & Neutral \\
\hline Overall experience about road safety in Phuket. & 3.15 & 0.850 & Neutral \\
\hline Overall, my road experience in Phuket is satisfactory. & 3.15 & 0.850 & Neutral \\
\hline
\end{tabular}

$\mathrm{N}=400$

Level of agreement: score 1.00-1.80 points = strongly disagree; score 1.81-2.60 points = disagree; score 2.61-3.40 points = neutral; score $3.41-4.20$ points $=$ agree; score $4.20-5.00$ points $=$ strongly agree

agreed on the necessity of the use of seatbelts and helmets in Phuket (Mean 4.27) and had the strong opinion that using mobile phones or other distractions while driving was not a good driving practice (Mean 4.28). The international tourists also admitted that knowledge about road safety in Phuket is a must and showed a desire to be informed about it before their arrival in the city (Mean 3.77). The mean value of this question is the same with the similar question "Road traffic laws and regulations in Phuket" (Mean 3.77). Regarding "road safety condition in Phuket" (3.57), the subjects care most about enforcing the speed limit (4.16).

The respondents were neutral about the feelings they had while driving in Phuket, including driving on the left side of the road, safety while travelling on the road, and the stress in Phuket's traffic jams (Mean 3.29). The city's road conditions are also neutral (Mean 3.19) but the lowest agreement in this -group of question is "local people drive carefully in Phuket" (Mean 2.95). This mean value is close to the other top three lowest scores for the agreement, i.e., "as a pedestrian, I feel safe using the roads in Phuket" (Mean 2.95), "it is not dangerous to travel on the roads in Phuket for the first time" (Mean 2.93), and "as a pedestrian,

I feel safe when crossing the streets in Phuket" (Mean 2.74). In overall, international tourists feel satisfied with

road experience in Phuket (Mean 3.15)

The results were analyzed to find the correlation between tourist's characteristic and perception by using ANOVA. Due to space restrictions, only issues that have a clear relationship are presented. First, international tourists older than 60 years agreed with the importance of using seatbelts and helmets more than other groups. Second, international tourists who graduated from the university and upper level has the higher agreement on the topic "other road safety conditions in Phuket" and strongly support to enforce the speed limit. This may imply that the educated people have more concern about road safety or imply that speed of car in Phuket causing a different feeling among groups of people may be a little too fast. Compared to other groups, international tourists with income higher than 3,500 USD agreed that road conditions in Phuket (such as lightings and lane widths) were sufficient enough. The group that mostly agreed using mobile phone was not a good practice was the tourists with the monthly income over 4,501 USD. Based on the statistical results obtained from 400 samples, 
other tourist's characteristic and perception related to road safety in Phuket had no significant relationship.

More information from subjects explained that this was based on the experiences from visiting many cities before. Naturally, they evaluated the road conditions in Phuket compared to their past experiences in their home country or countries they have visited before. As the road conditions vary much among countries, so their evaluation will also vary much according to their experiences. It is easily expected that those who came from countries of poor road conditions will evaluate the road conditions in Phuket higher and that those who have more experiences in many countries may have a generous perception. On the other hand, some authors have repetitive experiences that their friends coming to Phuket from some advanced countries including the United States and Japan complain the poor road conditions in Phuket, particularly from those older than 50 years. Thus more analyses and investigations are needed between demographic information of the tourists and their road transport perceptions.

More problems and concerns, received from the international tourist, while travelling in Phuket using road transport are presented in Table 3. The total number of comments was 450 , bigger than the number of the subjects, because each subject was allowed to write more than one comment. Among 450, 89 people did not answer the questions in this section, and thus 361 comments were written by 311 subjects, indicating that approximately $20 \%$ of the subjects wrote more than one comment. It is often the case with this type of survey that many subjects wrote nothing for additional comments, and it should be seriously considered that almost $80 \%$ of the subjects had some complaints about road conditions in Phuket, while the overall satisfaction with road conditions in Phuket was neutral (the mean was 3.15). From the viewpoint of the authors who have real experiences in the study area as local residents, complaints shown in Table 3 reflect more of actual situations. The number of concerns about too fast driving (the majority concern) is consistent with the attitudes of all groups surveyed.

On average, almost every international tourist had at least one problem about road transport from visiting Phuket. According to the interview result, 66 people (from 400 interviewees) ever witnessed one or more road accidents in Phuket. Their direct and indirect experiences may well give negative impressions or complaints on road conditions in Phuket, which is clearly reflected in the survey result.

In Table 4, international tourists' behaviors toward road were presented. Not only how they naturally behave when they need to use road transport in Phuket, obtaining road safety information both before and during the time in Phuket is also shared as a part of influencer to tourists' behavior, no matter from whichever source.

Table. 3 Problems and concerns while travelling on the road in Phuket

\begin{tabular}{lcc}
\hline Tourist's perception towards road safety in Phuket & Frequency & Percentage (\%) \\
\hline Problem and concerns & 58 & 12.9 \\
People drive very fast in Phuket. & 50 & 11.1 \\
Traffic in Phuket is busy with many vehicles. & 44 & 9.8 \\
People do not follow the traffic rules and regulations. & 39 & 8.7 \\
Drivers not pay attention to pedestrians in Phuket. & 33 & 7.3 \\
There is no proper lane in Phuket for motorbikes. & 26 & 5.7 \\
People drive recklessly in Phuket. & 26 & 5.8 \\
Roads are narrow in Phuket & 21 & 4.7 \\
People often drive without a helmet or without fastening a & 18 & 4.0 \\
seatbelt in Phuket & 12 & 2.6 \\
Driving in Phuket is dangerous. & 11 & 2.4 \\
There are not enough traffic lights in Phuket roads. & 8 & 1.8 \\
There are inexperienced drivers in Phuket. & 7 & 1.6 \\
Road traffic signs in Phuket are in bad condition. & 5 & 1.1 \\
There is no road safety information in Phuket. & 3 & 0.7 \\
Footbaths need to be improved in Phuket. & $\mathbf{8 9}$ & $\mathbf{1 9 . 8}$ \\
Driving motorbike is the most dangerous in Phuket. & $\mathbf{4 5 0}$ & $\mathbf{1 0 0}$ \\
No answer & & \\
\hline
\end{tabular}


Table. 4 Behaviors toward road transport in Phuket

\begin{tabular}{|c|c|c|}
\hline Behavior related to road safety and driving & Frequency & $\begin{array}{l}\text { Percentage } \\
\quad(\%)\end{array}$ \\
\hline \multicolumn{3}{|l|}{ Did you drive in Phuket? } \\
\hline No & 319 & 79.7 \\
\hline \multicolumn{3}{|l|}{$\begin{array}{c}3.8 \%, \text { both motorbike \& car }=1.5 \%, \\
\text { other }=0.5 \%\end{array}$} \\
\hline Total & 400 & 100 \\
\hline \multicolumn{3}{|l|}{$\begin{array}{c}\text { Type of vehicles used during vacation in } \\
\text { Phuket (Multiple answers) }\end{array}$} \\
\hline Local taxi (Tuk Tuk) & 193 & 48.3 \\
\hline Rental motorbike & 73 & 18.3 \\
\hline Metered taxi & 67 & 16.8 \\
\hline Local bus & 65 & 16.3 \\
\hline Rental car & 45 & 11.3 \\
\hline Coach & 32 & 8.0 \\
\hline Bicycle & 5 & 1.3 \\
\hline $\begin{array}{c}\text { Other: Friend's car }=1.1 \% \text {, Van }= \\
2.8 \%\end{array}$ & 15 & 3.8 \\
\hline Total & 495 & 123.8 \\
\hline \multicolumn{3}{|l|}{ Time spent on the road in Phuket (Per day) } \\
\hline$<1$ hour & 114 & 28.5 \\
\hline $1-2$ hours & 67 & 16.7 \\
\hline 2-3 hours & 104 & 26.0 \\
\hline 3-4 hours & 113 & 28.3 \\
\hline$>4$ hours & 2 & 0.5 \\
\hline Total & 400 & 100 \\
\hline
\end{tabular}

Period of time on the road in Phuket

(Multiple answers)

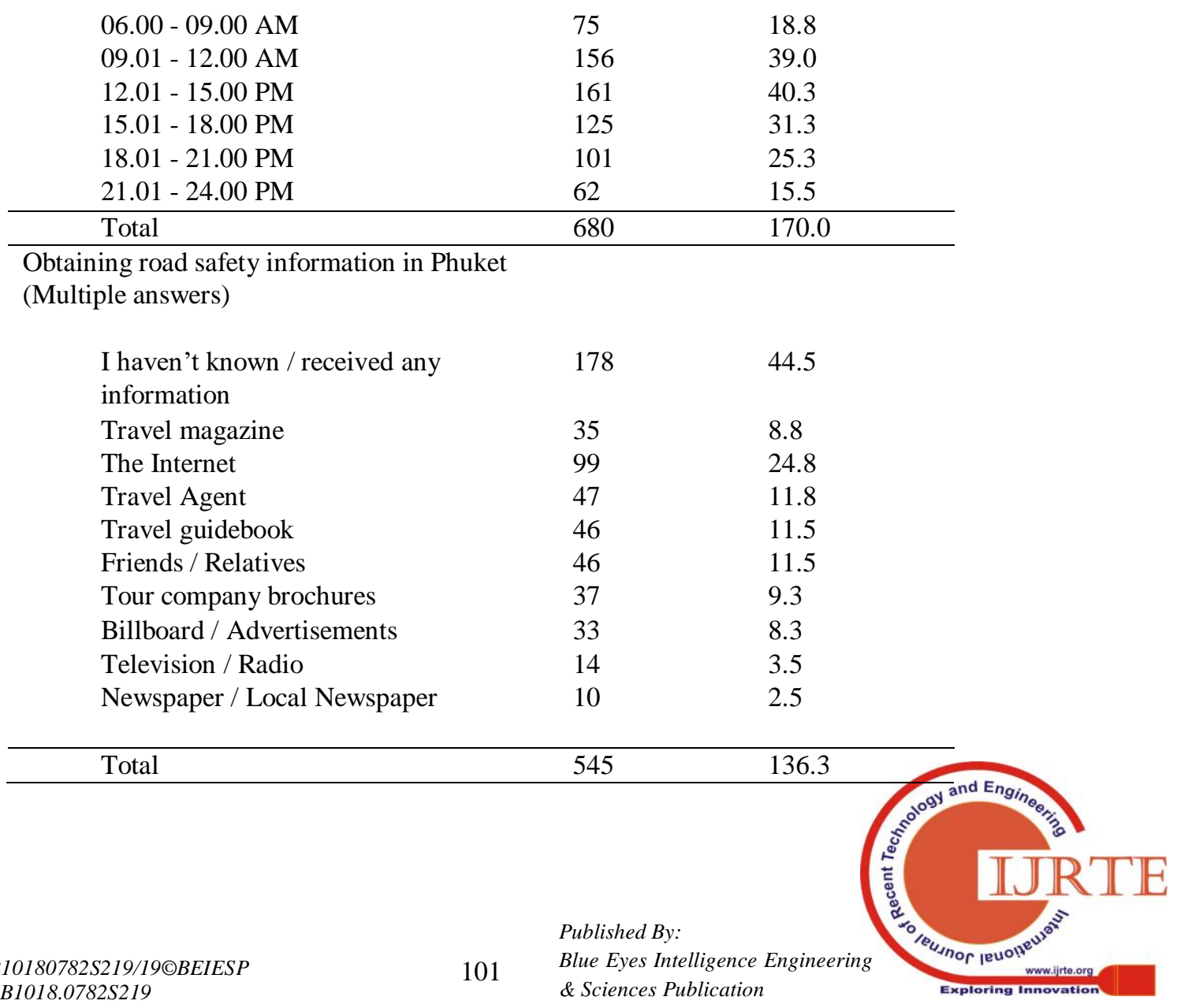


A fact, that local people and a large number of tourists well perceived, is that rental car in Phuket is one of the cheapest and most convenient choices for travelling. It is normal that hiring a driving service is expensive in Thailand while the number of public transports is very limited and they usually cover only the main routes in the province. In Phuket, it is more apparent for both prices and the number of available public transports when compared to other big cities including Bangkok, the capital city in Thailand. Even so, almost $80 \%$ (310 among 400) of the subjects had no experience of driving in Phuket, meaning that the majority of the subjects avoided driving in Phuket for some reason. In addition, using local small taxis (Tuk Tuk, a traditional type of public car in Thailand) was the most popular choice in a quite different numbers compared to others even they had to spend time on the road 1 to 4 hours (the frequency of time spent on the road is close for almost every range from 1 to 4 hours). With this long range of time for transportation (with the close or even cheaper rate for rental car), it affirmed the fact that tourists preferred not to drive by their own. Most travelling time was from 9 am - 6 pm (top 3) which was still the convenient time to drive without much necessity of road familiarity. Almost half of the interviewed tourists never received any information about road safety in Phuket. So, they naturally behave and made any decisions for transportation in Phuket from their own experiences. Not surprisingly, the major source of information the tourists obtained was from the Internet (1/4) while most of them agreed that it is necessary to be informed of how to drive safely in Phuket before arrival (Table 2). As one of the most famous area for international tourists, any improvements should be more useful if they are done according to the international points of view. A suggestion from this result is that it may be an idea to distribute a small booklet on Phuket road conditions and regulations when they arrive.

Recommendation for the safety of road transportation from this surveyed group is presented in Table 5. Approximately $70 \%$ of the subjects shared some feedbacks for the improvement in spite most of the questions listed for them are fundamental needs for a safety road. This infers that the road safety in Phuket was still below the world standards compared to roads in developed countries that do not usually encounter these basic problems. Enforcing regulations, laws and penalty for the traffic offenders is the major recommendation. A hardly denied thing is that the use of traffic regulations in Thailand is not truly strict especially in provinces, compared to developed countries, and this is also a critical reason of high accident rate.

In overall, on the other hand, most international tourists seem to be willing to use public transportations including Tuk Tuk and taxis, instead of driving themselves. Note that Tuk Tuk (the majority of available option for transportation within the city) is not the preferred choice for the local people due to its high fee compared to other options and to general transportation cost in other cities and they are regarded as tourist vehicles. As shown in Table 4, however, only 65 people $(16 \%)$ used local buses. This means that "public transportation" in Table 2 (using public transportation services are safe in Phuket) mostly represents Tuk Tuk and taxis, but not public bus. One of the advantages of Phuket to attract tourists is a relatively low accommodation and meal costs, but high fees of Tuk Tuk, taxis, and vans compared to them are notorious. Thus it is necessary to improve more affordable public transportation systems.

Another point to note is that, although $80 \%$ of the subjects never drive, $80 \%$ of the subjects also complained poor road conditions. It means that their perceptions of poor road conditions came from their experience as pedestrians and passengers. Thus it is also suggested that local residents' driving manners be improved. From additional questions during the interview, mainly for the critical issues, 27 persons $(6.8 \%)$ responded that road safety of everywhere is similar, 56 persons $(14.0 \%)$ has no any problem with transportation in Phuket for their traveling plan, 16 persons $(4.0 \%)$ were unhappy with Phuket's traffic jam, and 15 persons $(3.8 \%)$ would not return if they need to come with their babies or if they need to drive. By considering the income from foreign tourist $(207,874$ million Baht in 2013) [6], the potential loss from this group of people due to the issue of road safety is nearly 7,899 million Baht a year.

Table 5. Road safety recommendation

Tourist's perception that affects
road safety.


Bad road condition must be 4 improved.

An appropriate public 3 transportation system is needed.

No answer

125

Total answer

325

27.8

Total feedback

450

72.2

\section{CONCLUSION}

This study reported the result of our questionnaire survey to 400 international tourists to Phuket, Thailand on their perceptions of road conditions and manners with correlational analyses. Most of correlations confirmed that people of higher ages, with more income, and with more education tend to have a higher awareness and concern about the road conditions and manners in Phuket, though the basic tendency of perceptions are more similar than expected. Although the average satisfaction with the road conditions in Phuket was not bad, $80 \%$ of the subjects complained one or more risks in their descriptions while only $20 \%$ drove by themselves, indicating that, regardless of their driving experience in Phuket, the majority fostered similar negative perceptions towards the road transport. This suggests that it is urgent to improve the road conditions and manners if Phuket wants to continue to be a high-rated popular beach resort and to develop more as a safe tourist destination. In particular, the survey revealed a high demand of the information about road conditions and regulations in Phuket or Thailand in general before they started their stay, enabling them to prepare themselves. Based on these results, some suggestions for policy-making were also discussed. However, a more detailed investigation is necessary in terms of relations between demographic characteristics of the tourists and their perceptions of road transport, as well as economic losses particularly in relation to tourism industry due to poor road conditions and manners. The perceptions among local residents are also to be investigated.

\section{ACKNOWLEDGMENT}

The financial support of National Science and Technology Development Agency (NSTDA), under the project entitled "An analysis of green gross provincial product (GPP) of Phuket, a tourist city" under Grant No. P-16-50628, is gratefully acknowledged.

\section{REFERENCES}

1. T. P. N. Sakolnakorn, A. Naipinit, P. Kroeksakul, "Sustainable Tourism Development and Management in the Phuket Province, Thailand," Asian Social Science, vol. 9, no. 7, pp. 75-84, 2013.

2. Tourism Authority of Thailand (TAT), "Thailand Tourism Statistical Report 2013," Bangkok, 2013.

3. V. Kasantikul, J.V. Ouellet, T. Smith, J. Sirathranont, V. Panichabhongse, "The role of alcohol in Thailand motorcycle crashes," Accident Analysis \& Prevention, vol. 37, no. 2, pp. 357-366, 2005.

4. P. Suriyawongpaisal, S. Kanchanasut, "Road traffic injuries in Thailand: trends, selected underlying determinants and status of intervention," Injury control and safety promotion, vol. 10, no. 1-2, pp. 95-104, 2013.

5. Thailand Road Safety Network, "Thai national status report on road safety 2014,” 1st ed., Khon Kaen Printing Ltd.Part., 2016 (in Thai).
6. National Statistical Office, "Phuket Provincial Statistical Report," (in Thai). Retrieved February 17, 2019 from http://phuket.nso.go.th/index.php?option=com_content $\&$ view=article $\&$ id=132\&Itemid=507

7. National Statistical Office, "Area-level statistical development plan Phuket Area no. 2 (year 2018-2021)," 2018 (in Thai).

8. E.B. Goldstein, "Sensation and perception," Wadsworth, Cengage Learning, Retrieved October 24, 2016 from http://zhenilo.narod.ru/main/students/Goldstein.pdf

9. S.S. Smith, M.S. Horswill, B. Chambers, M. Wetton, "Hazard perception in novice and experienced drivers: The effects of sleepiness," Accident Analysis \& Prevention, vol. 41, no. 4, pp. 729733, 2009.

10. A.D. Tasci, Y. Boylu, "Cultural comparison of tourists' safety perception in relation to trip satisfaction," International Journal of Tourism Research, vol. 12, no. 2, pp. 179-192, 2010.

11. The Thaiger, " 50,000 baht fine and 3 months jail for driving without a license - transport law upgrades,". Retrieved March 9, 2019 from https://thethaiger.com/news/national/50000-baht-fine-and-3-monthsjail-for-driving-without-a-license-transport-law-upgrades

12. The pattaya news, "Pattaya Police to crack down on foreign drivers without licenses, confiscate vehicle,”. Retrieved March 9, 2019 from https://thepattayanews.com/2018/05/10/pattaya-police-to-crack-downon-foreign-drivers-without-licenses-confiscate-vehicle/

13. B.W. Ritchie, A. Tkaczynski, P. Faulks, "Understanding the motivation and travel behavior of cycle tourists using involvement profiles," Journal of Travel \& Tourism Marketing, vol. 27, no. 4, pp. 409-425, 2010 .

14. A. Jonas, Y. Mansfeld, S. Paz, I. Potasman, "Determinants of health risk perception among low-risk-taking tourists traveling to developing countries," Journal of Travel Research, vol. 50, no. 1, pp. 87-99, 2011.

15. P. Siriphakdee, "Results of a study analyzing the causes of road accidents by Thai and foreign nationals in Pai district, Mae Hong Son province," Lanna Public Health Journal, vol. 5, no. 1, pp. 89-95, 2013.

16. Tourism Authority of Thailand (TAT), "Thailand Tourism Statistical Report 2014," Bangkok, 2015.

17. W.G. Cochran, "Sampling techniques," $3^{\text {rd }}$ ed. John Wiley \& Sons, New York, 1977.

18. P. Eiamtrakul, Y. Pimonsathean, S. Narinsilp, "The study of urban factors influencing on road safety through public participation process," Journal of Architecture and Planning Research and Studies, vol. 7, no. 1, pp. 59-71, 2015.

19. G. Yannis, E. Papadimitriou, C. Antoniou, "Multilevel modeling for the regional effect of enforcement on road accidents," Accident Analysis \& Prevention, vol. 39, no. 4, pp. 818-825, 2007. 